\title{
Emergency reversal of vitamin-K antagonists related over-anticoagulation: case report and brief overview on the role of Prothrombin Complex Concentrate
}

\section{Rapida correzione dell'eccessiva anticoagulazione da antagonisti della vitamina K: caso clinico e breve inquadramento del ruolo del Complesso Protrombinico Concentrato}

\author{
Stefania Angela Di Fusco'1, Nadia Aspromonte1, Stefano Aquilani1, \\ Luca Mele2, Furio Colivicchi ${ }^{1}$
}

\begin{abstract}
Emergency reversal of vitamin-K antagonists related over-anticoagulation: case report and brief overview on the role of Prothrombin Complex Concentrate. S.A. Di Fusco, N. Aspromonte, S. Aquilani, L. Mele, F. Colivicchi.

Oral anticoagulation is a widely used treatment and atrial fibrillation $(\mathrm{AF})$ is the most frequent indication. We review the therapeutic options on an important clinical challenge: rapid reversal anticoagulation in the setting of an urgent invasive procedure. We report a case of a 71-year-old man treated with warfarin who was over-anticoagulated when presented to the emergency department for syncope due to severe bradiarrhythmia and needed temporary pacing. Intravenous infusion of vitamin-k was not adequate for rapid
\end{abstract}

\begin{abstract}
reversal over anticoagulation whereas the administration of a Prothrombin Complex Concentrate (PCC) was able to quickly reverse anticoagulant activity and allowed the performance of an urgent invasive procedure without hemorrhagic complication. The aim of this paper is to draw attention to possible therapeutic strategies to reduce the risk of bleeding related to over-anticoagulation with vitamin-K antagonists (VKAs) in case of urgent invasive procedure, emphasizing the role of PCC in keeping with national and international guidelines.

Keywords: vitamin-K antagonist; reversal of over-anticoagulation, Prothrombin Complex Concentrate.
\end{abstract}

Monaldi Arch Chest Dis 2013; 80: 184-188.

From ${ }^{1}$ Cardiovascular Department and 2 Transfusion Medicine Department, San Filippo Neri Hospital, Roma, Italy.

Corresponding author: Stefania Angela Di Fusco; Cardiovascular Department, San Filippo Neri Hospital; Via G. Martinotti 20; I-00135 Roma, Italy; Fax: 39-06-33062489; Telephone: 39-06-33062467; E-mail address: doctstefania@hotmail.com

\section{Case report}

A 71-year-old male was admitted to the emergency department of our hospital because of syncope with contusive head trauma, and previous recurrent episodes of dizziness. The patient had a past medical history of arterial hypertension, chronic renal failure, and persistent AF. He was treated with amiodarone for rhythm control, warfarin for thrombo-embolic prevention (CHA2DS2-ASc 2; HASBLED 3), and angiotensin-converting-enzyme inhibitor for hypertension. On admission, the patient's blood pressure was $130 / 70 \mathrm{mmHg}$ and his pulse rate was $60 \mathrm{bpm}$.

A thorough physical examination revealed no abnormal findings besides an epistaxis which was resolved quickly with direct pressure. The neurological examination revealed no neurological deficits and a brain computed tomography excluded structural abnormalities related to syncopal episode.

The electrocardiogram (ECG) at admission showed sinus rhythm, left bundle branch block and first degree atrio-ventricular block, with a PR inter- val of 220 msec (Fig. 1). Initial laboratory evaluation was remarkable for an international normalized ratio (INR) of 8.05, a high creatinine level (2.65 $\mathrm{mg} / \mathrm{dl}$ ) with serum electrolytes within normal range and mild anemia (hemoglobin value $13 \mathrm{~g} / \mathrm{dl}$ ). Due to the high risk of bleeding related to the high level of INR and the head trauma, Vitamin K $10 \mathrm{mg}$ was administered by slow intravenous infusion to reverse anticoagulation.

During observation in the emergency department a few hours later, the patient experienced a further episode of dizziness. The ECGs performed immediately after revealed a total atrio-ventricular block, junctional rhythm with the same QRS morphology as sinus rhythm and isorhythmic atrial ectopic activity, with a heart rate of 30 beats per minute (Fig. 2). The blood pressure was $110 / 70$ $\mathrm{mmHg}$. Due to the persistent severe bradycardia despite the use of atropine bolus and isoprenaline infusion, and with the patient symptomatic for deep asthenia, temporary transcutaneous pacing was applied and the patient was scheduled for urgent implantation of temporary transvenous pacing. Before 


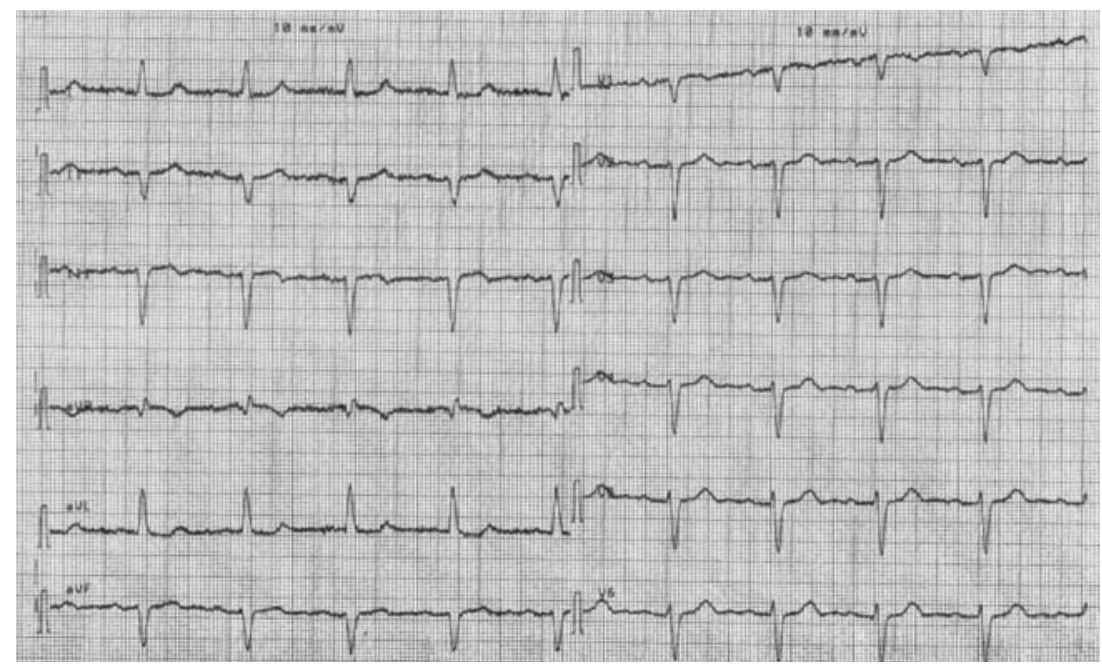

Figure 1. - ECG at admission showing a sinus rhythm, left bundle branch block and first degree atrio-ventricular block.
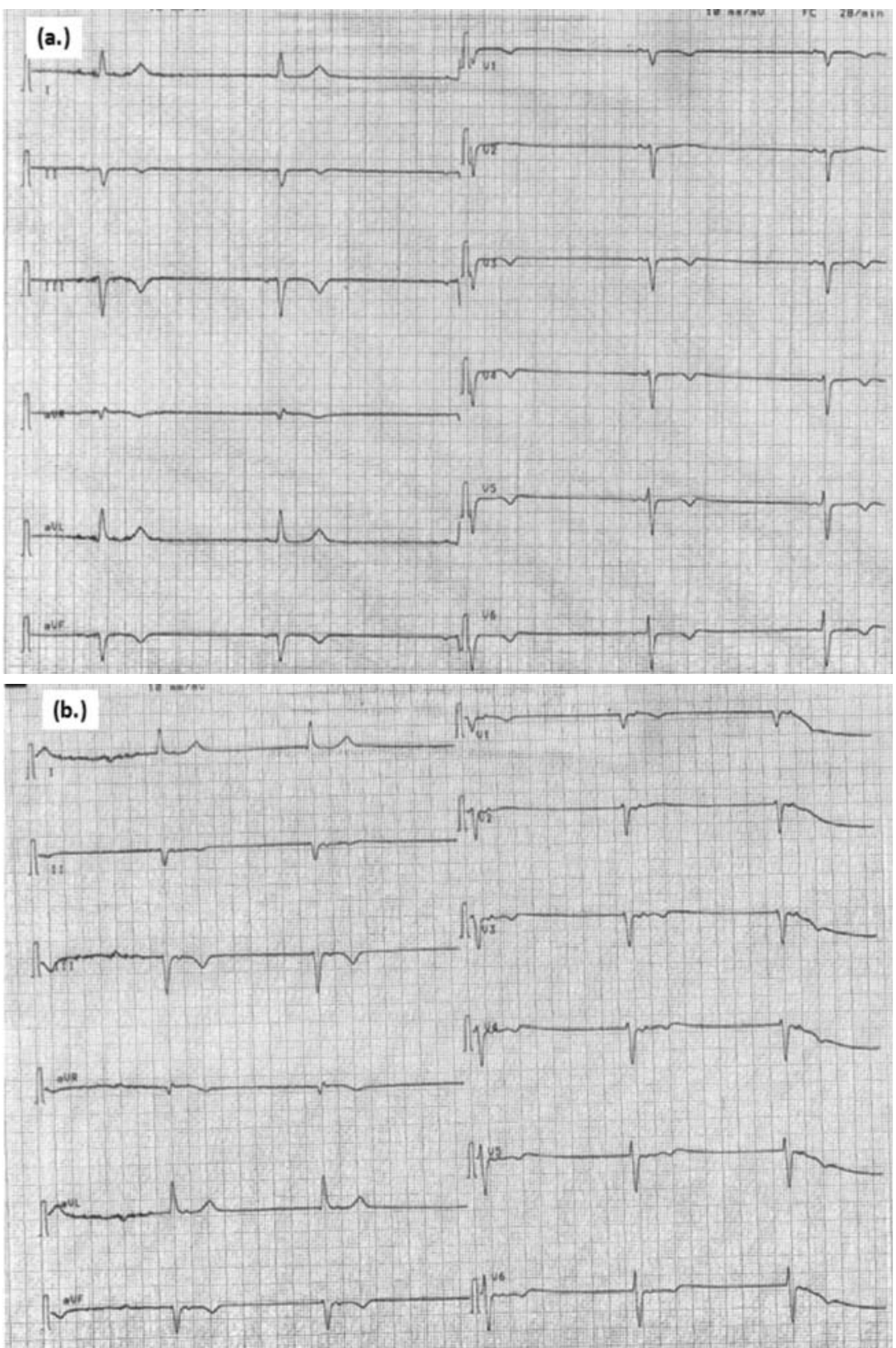

Figure 2. - ECG during symptoms: total atrio-ventricular block, junctional rhythm with the same QRS morphology as sinus rhythm and isorhythmic atrial ectopic activity (a. preceding QRS, b. following QRS) with heart rate of 30 beats per minute. performing the invasive procedure coagulation parameters were reassessed. The INR was 4.65 with a Prothrombin Time (PT) equal to $16 \%$. For the purpose of reducing procedural hemorrhagic risk, we discussed the case with a consultant hematologist and opted for a therapeutic intervention to immediately reverse the patient's over-anticoagulation. We administered a three factor Prothrombin Complex Concentrate (PCC), a combination of concentrates of factors II, IX and $\mathrm{X}$, supplemented with small amounts of heparin. One hour after administration of PCC at a dose of $35 \mathrm{UI} / \mathrm{Kg}$ (equal to a total amount of 2800 UI), the INR was 1.93. The dose was established, according to the formula proposed on the label: body weight $(\mathrm{kg}) \mathrm{x}$ desired PT level rise $\mathrm{x}$ 1.2. The desired PT level rise was calculated as: target level of PT minus the present level of PT, and our target PT was $45 \%$ equivalent to an INR value of 1.8 .

A transvenous temporary pacing electrode was promptly inserted via the right femoral vein. In order to reduce the risk of complications an ultrasound-guided approach to central venous cannulation was used. The pacing lead was advanced under fluoroscopic guidance and placed in the right ventricular apex. No implant-related complications were observed during the procedure. The next day the temporary pacing was replaced by a permanent pacing with a subsequent course uncomplicated.

\section{Discussion}

We report a case of perioperative management of over-anticoagulation in a patient with a history of $\mathrm{AF}$ who required immediate reversal of anticoagulant activity. AF is the most frequent indication for anticoagulation and according to a recent nationwide observational study, it is estimated that $2 \%$ of the Italian population has a diagnosis of $\mathrm{AF}$, and $46 \%$ of these patients receive anticoagulant therapy [1] and vitamin $\mathrm{K}$ antagonists (VKAs) are still the most commonly prescribed oral-anticoagulants despite the introduction in the market of novel oral-anticoagulant (NAO). In patients who need urgent surgery or an invasive procedure the optimal strategy to reverse anticoagulation has not been clearly 
defined. The therapeutic strategy described here, intravenous administration of Vitamin $\mathrm{K}$ followed by PCC infusion, was performed successfully with a favorable outcome. At present, therapeutic options to reverse over-anticoagulation with vitamin-k antagonists include: omission of a dose of VKA, administration of an oral or intravenous dose of vitamin K, use of fresh frozen plasma (FFP), administration of PCC, or recombinant factor VIIa. The clinical setting (major bleeding, need of urgent surgery, etc) in addition to the patient's INR value must be taken into account to establish the most appropriate strategy to reverse anticoagulation in each case. The first two options are inadequate in emergency cases since they require several hours for the full recovery of coagulation factors. Human plasma has traditionally been the keystone of treatment for reversing over-anticoagulation in most emergency cases. PCC, which was originally developed to treat hemophilia B (Factor IX deficiency) [2], is now indicated as first choice treatment for emergency reversal of anticoagulant therapy in life threatening major bleeding and in perioperative settings, although fewer studies support the latter indication. Commercially available PCCs, depending on their content of clotting factors, are referred as three-factor PCC, which contains significant levels of factors II, IX, and X, or four-factor PCC, which also contains factor VII in significant amounts. The place of recombinant activated factor VIIa in the setting of emergency reversal of anticoagulation needs further evaluation because its risk-benefit profile is not clear [3]. According to the Italian Federation of Centres for the Diagnosis of Thrombosis and Monitoring of Antithrombotic Therapies (FCSA), PCC is the treatment of choice for acute reversal of oral VKAs in both cases of major bleeding and urgent surgery [4]. Liumbruno et al. [5], as Italian Society of Transfusion Medicine and Immunohaematology Working Party, suggest a $2 \mathrm{C}+$ grade of recommendation for PCC as anticoagulation therapy reversion. These recommendations are in accordance with other international guidelines. The American College of Chest Physicians' guidelines also suggest rapid reversal of anticoagulation with four-factor PCC rather than with plasma in case of major bleeding, however they don't give clear recommendations for the treatment of patients who need urgent surgery [6]. The recently updated consensus guidelines of the Australasian Society of Thrombosis and Haemostasis state that in the setting of urgent surgery PCC can be used to reverse anticoagulant effect [7]. Despite these recommendations, the use of PCC in clinical practice remains limited for various reasons such as the prevalent accessibility of FFP, and possible inconsistent application of guidelines. PCC has several advantages over FFP (Table 1). Cost-effectiveness analysis shows that PCC compared to FFP is a more cost-effective strategy in several scenarios [8]. PCC requires a shorter time for administration, and time is critically important in emergency cases. Before FFP can be administered, compatibility testing is required and the plasma must be thawed and then warmed. In contrast to FFP, PCC contains higher amounts of the vitamin K-dependent clotting factors per unit of volume. Indeed, the overall clotting factor concentration is approximately 25 times higher than in FFP [9]. Therefore smaller volumes of PCC are necessary to achieve an increase in coagulation factor level, therefore minimizing the risk of fluid overload and decreasing the infusion's time. PCC is associated with lower risks of infectious agents' transmission because it undergoes viral inactivation, whereas most FFP products are not virally inactivated.

In spite of such clear advantages, there is still a lack of expert consensus on the optimal dose of PCC to use. Literature data indicates that individualized dosing, based on body weight, basal INR, and target INR in each clinical case, is more effective at reversing anticoagulation than a standard dose. In the majority of studies, the dose of threefactor PCC (expressed as units of the factor IX component) used was 25-50 units/kg [10]. The dosage prescribed in our case was established according to the formula suggested by the label, considering that an infusion of $1 \mathrm{UI} / \mathrm{Kg}$ of PCC increases the PT by $1 \%$. The dosage so calculated was lower than that recommended by FCSA [4] (Table 2). In fact, our target was an INR between 1.5 and 2 , whereas in the FCSA practical guide the goal of the proposed treatment is an INR $<1.5$. However, the dose administered in our case was consistent

Table 1. - Main differences between PCC and FFP

\begin{tabular}{lcc}
\hline & PCC & FFP \\
\hline - Time for the administration & Immediate & After compatibility testing and thawing \\
\hline - Infusion volume & Small & Large \\
\hline - Risk of infection Coagulation Factors contained & Minimal & Higher \\
\hline - Risk of TRALI & II, VII*, IX, X & All \\
\hline - Risk of thrombotic complications & Unlikely & Present \\
\hline
\end{tabular}

FFP, fresh frozen plasma; PCC, Prothrombin Complex Concentrate; TRALI, transfusion-related acute lung injury.

* In significant amounts only in 4-factor PCC. 
Table 2. Suggested dose of PCC to reverse the anticoagulant effect of VKAs according to patient's initial INR in case of urgent surgery

\begin{tabular}{lll}
\hline Author, year (reference) & Initial INR & PCC dose \\
\hline & INR $<2$ & $20 \mathrm{IU} / \mathrm{kg}$ \\
Limbruno, $2009(5)$ & INR 2-4 & $30 \mathrm{IU} / \mathrm{kg}$ \\
& INR $>4$ & $50 \mathrm{IU} / \mathrm{kg}$ \\
\hline & INR 1.5-2 & $20 \mathrm{IU} / \mathrm{kg}$ \\
Crippa, 2010 (4) & INR 2.1-3.9 & $30 \mathrm{IU} / \mathrm{kg}$ \\
& INR 4-5.9 & $40 \mathrm{IU} / \mathrm{kg}$ \\
& INR $>6:$ & $50 \mathrm{IU} / \mathrm{kg}$ \\
\hline
\end{tabular}

INR, international normalized ratio; PCC, Prothrombin Complex Concentrate; VKA: vitamin-K antagonist.

with that proposed by Colomina et al. in their review on perioperative use of PCC [10]. Considering the long anticoagulant effect of warfarin and the shorter half-life of coagulation factor concentrates, to treat vitamin-k dependent over-anticoagulation the PCC should always be used in association with vitamin-k supplement $[4,5,6,7,10,11]$.

This case highlights the difficulties faced by physicians in emergency perioperative management of patients treated with oral anticoagulant. In each case the risk of thrombotic complication due to treatment with haemostatic agents has to be weighed against the potential benefit of rapid reversal of the effect of VKAs (risk of intraoperative bleeding or the consequences of procedure deferral). The routine clinical use of NOAs is changing the therapeutic landscape (Fig. 3). According to the European
Heart Rhythm Association practical guide, the administration of PCC can be considered in patients with life-threatening bleeding, whereas unfortunately, there are insufficient data available to optimally guide management of patients undergoing an urgent surgical intervention [12].

\section{Riassunto}

La terapia anticoagulante orale è ampiamente utilizzata in diversi contesti clinici e la fibrillazione atriale è la più comune indicazione. Nel presente articolo riesaminiamo le opzioni terapeutiche in un contesto clinico molto critico: la rapida correzione di una eccessiva anticoagulazione con antagonisti della vitamina $K$, in caso di necessità di procedura invasiva urgente. Riportiamo il caso clinico di un uomo di 71 anni, in profilassi antitrombotica con warfarin che presentava un INR sopra-terapeutico quando $\grave{e}$ giunto in Pronto soccorso in seguito ad episodio sincopale dovuto ad una importante bradiaritmia che richiedeva il posizionamento di un pacemaker temporaneo transvenoso. $L$ 'infusione di vitamina $K$ non è stata sufficiente a correggere rapidamente l'anticoagulazione, mentre la somministrazione di Complesso Protrombinico Concentrato (PCC) ha permesso una rapida correzione dell'anticoagulazione. E stata quindi eseguita la procedura invasiva urgente senza complicanze emorragiche. Nella discussione viene posta l'attenzione sulle possibili strategie 
terapeutiche volte a correggere rapidamente l'anticoagulazione in caso di procedure invasive urgenti, sottolineando il ruolo del PCC in accordo con le linee guida nazionali ed internazionali.

\section{ABBREVIATIONS AND ACRONYMS}

AF: atrial fibrillation

CHA2DS2-ASc: congestive heart failure or left ventricular dysfunction, hypertension, age $\geq 75$ (doubled), diabetes, stroke (doubled)-vascular disease, age 65-74 and sex category (female) ECG: electrocardiogram

FCSA: Italian Federation of Centres for the Diagnosis of Thrombosis and Monitoring of Antithrombotic Therapies

FFP: fresh frozen plasma

HASBLED: hypertension, abnormal renal/liver function, stroke, bleeding history or predisposition, labile INR, elderly age, drugs/alcohol concomitantly

INR: international normalized ratio

NOA: novel oral-anticoagulant

PCC: Prothrombin Complex Concentrate

PT: Prothrombin Time

VKA: vitamin-K antagonist.

\section{References}

1. Zoni-Berisso M, Filippi A, Landolina M, et al. Frequency, patient characteristics, treatment strategies, and resource usage of atrial fibrillation (from the Italian Survey of Atrial Fibrillation Management [ISAF] study). Am J Cardiol 2013; 111(5): 705-11

2. Key NS, Negrier C: Coagulation factor concentrates: past, present, and future. Lancet 2007, 370: 439-448

3. Rosovsky RP, Crowther MA. What is the evidence for the off-label use of recombinant factor VIIa (rFVIIa) in the acute reversal of warfarin? ASH evidence-based review 2008. Hematology Am Soc Hematol Educ Program 2008; 1: 36-38.
4. Crippa L, Erba N, Falanga A et al. Pazienti in terapia anticoagulante orale, che cosa fare in caso di: Emorragia intracranica, Emorragie maggiori, Chirurgia di emergenza, Emorragie minori (con o senza eccessiva anticoagulazione), Correzione di eccessiva anticoagulazione in assenza di emorragie. FCSA, Settembre 2010.

5. Liumbruno G, Bennardello F, Lattanzio A, Piccoli P, Rossetti G; Italian Society of Transfusion Medicine and Immunohaematology (SIMTI) Working Party Recommendations for the use of antithrombin concentrates and prothrombin complex concentrates. Blood Transfus 2009; 7(4): 325-34.

6. Holbrook A, Schulman S, Witt DM et al.; American College of Chest Physicians. Evidence-based management of anticoagulant therapy: Antithrombotic Therapy and Prevention of Thrombosis, 9th ed: American College of Chest Physicians Evidence-Based Clinical Practice Guidelines. Chest 2012; 141(2 Suppl): e152S-84S.

7. Tran HA, Chunilal SD, Harper PL, Tran H, Wood EM, Gallus AS; Australasian Society of Thrombosis and Haemostasis (ASTH). An update of consensus guidelines for warfarin reversal. Med J Aust 2013; 198(4): 198-9.

8. Guest JF, Watson HG, Limaye S. Modeling the cost-effectiveness of prothrombin complex concentrate compared with fresh frozen plasma in emergency warfarin reversal in the United kingdom. Clin Ther 2010; 32(14): 2478-93.

9. Schulman S, Bijsterveld NR. Anticoagulants and their reversal. Transfus Med Rev 2007; 21: 37-48.

10. Colomina MJ, Díez Lobo A, Garutti I, Gómez-Luque A, Llau JV, Pita E. Perioperative use of prothrombin complex concentrates. Minerva Anestesiol 2012; 78(3): 358-68.

11. Kalus JS. Pharmacologic interventions for reversing the effects of oral anticoagulants. Am J Health-Syst Pharml 2013; 70 (Suppl 1): S12-21.

12. Heidbuchel H, Verhamme P, Alings $\mathrm{M}$ et al.; European Heart Rhythm Association. European Heart Rhythm Association Practical Guide on the use of new oral anticoagulants in patients with non-valvular atrial fibrillation. Europace 2013; 15(5): 625-51. 